\title{
Low Blood Albumin and Cholesterol Levels Affecting the Conception Rate of Cross Bred Cows with Ovsynch Protocol
}

\author{
D. Sengupta ${ }^{1}$ and S.K. Sheetal ${ }^{2} *$ \\ Department of Veterinary Gynaecology and Obstetrics, Bihar Veterinary College, \\ Bihar Animal Sciences University, Patna, Bihar, India \\ *Corresponding author
}

\section{A B S T R A C T}

This study was undertaken to evaluate the effect of serum albumin and cholesterol level on the conception rate with Ovsynch protocol in cross-bred cattle. Fifty cross-bred cows were selected and divided into two groups- low albumin cholesterol (LAC; $<3 \mathrm{mg} / \mathrm{dl}$ albumin

\section{Keywords}

Cholesterol, Albumin,

Progesterone, Conception rate, Ovsynch protocol

\section{Article Info}

Accepted:

24 July 2020

Available Online:

10 August 2020 and $150 \mathrm{mg} / \mathrm{dl}$ cholesterol) and high albumin cholesterol group (HAC; > $3.5 \mathrm{mg} / \mathrm{dl}$ albumin and $220 \mathrm{mg} / \mathrm{dl}$ cholesterol). The conception rate of LAC and HAC was $10 \%$ and $38 \%$ respectively that differed significantly $(\mathrm{P}<0.05)$. Return to heat on or before day 22 was significantly higher in LAC $(60.7 \%)$ compared to HAC $(32.3 \%)$. Pregnant cows of LAC group $(n=5)$ had significantly higher albumin and cholesterol level $(3.4 \pm 0.04 \mathrm{mg} / \mathrm{dl}$ and $194.78 \pm 3.75 \mathrm{mg} / \mathrm{dl}$ respectively) than their non-pregnant counterpart $(3.29 \pm 0.01 \mathrm{mg} / \mathrm{dl}$ and $146.99 \pm 1.44 \mathrm{mg} / \mathrm{dl}$ respectively; $\mathrm{n}=30$ ). On days $12,14,16$ and 18 the progesterone concentration of non-pregnant cows of LAC group $(2.9 \pm 0.04 \mathrm{ng} / \mathrm{ml}, 2.1 \pm 0.03 \mathrm{ng} / \mathrm{ml}$, $1.8 \pm 0.03 \mathrm{ng} / \mathrm{ml}, 0.7 \pm 0.01 \mathrm{ng} / \mathrm{ml}$ respectively) was significantly lower than day 65 pregnant cows of HAC group $(5.2 \pm 0.08 \mathrm{ng} / \mathrm{ml}, 4.7 \pm 0.11 \mathrm{ng} / \mathrm{ml}, 5.3 \pm 0.09 \mathrm{ng} / \mathrm{ml}, 5.7 \pm 0.07 \mathrm{ng} / \mathrm{ml}$ respectively).From the results it can be inferred that low cholesterol and albumin level directly decreases the blood progesterone level and initiates early luteolysis, both are instrumental in early embryonic death and low conception rate with Ovsynch protocol. Since blood cholesterol is the main precursor for the synthesis of progesterone by the corpus luteum and $90 \%$ of progesterone in blood is bound to albumin, their deficiency directly affects the blood progesterone level. Blood albumin and cholesterol should always be checked and corrected before the start of Ovsynch protocol.

\section{Introduction}

Large dairy farms are on the rise in India wherein one of the most important factors limiting reproductive performance of dairy cows is heat detection. Traditional methods of heat detection are inefficiently applied on large dairy herds due to less number of laborers deployed for this task per cow. Moreover cows exhibit different degree of secondary signs of heat and most of the estrus detection in these farms is based on these secondary signs. According to recent studies, less than $50 \%$ of the lactating dairy cows 
were detected in estrus (Washburn et al., 2002), resulting in prolonged interinsemination intervals and less profit for the dairy producers.

One way to solve this problem is to control follicular dynamics so as to make all cows ovulate at a fixed time thus eliminating the need of estrus detection. Ovsynch protocol (injection of GnRH 7 days before and 48 hours after $\mathrm{PGF}_{2 \alpha}$ ) is one such protocol that facilitates synchronization of follicular development, luteal regression and time of ovulation with minimal need of estrus detection (Pursley et al., 1997a,b). However, great variations in conception rate have been reported with Ovsynch protocol (Stevenson et al., 1999 and Jobst et al., 2000).

We have therefore sought to find out whether difference in serum biochemistry specially albumin and cholesterol affects the conception rate with Ovsynch protocol. Cholesterol and albumin level in the blood is mainly controlled by the level of nutrition and liver function. Since there are degrees of negative energy balance especially in high yielder cross-bred cattle, level of these two biochemical parameters varies greatly. Cholesterol being the precursor for the synthesis of progesterone by the corpus luteum (Stoccoet al.,2005, Roostaeeet al.,2008) and albumin being the carrier of progesterone in the blood (Harrison et al., 1987) might regulate the level of circulating progesterone which might affect the conception rate. This work has therefore been taken up to test these effects.

\section{Materials and Methods}

Normal cycling cross-bred cows $(n=50)$ from farms in and around Patna were tested for blood albumin and cholesterol level and were divided into two groups of fifty each. Group A $(n=50)$ had blood albumin and cholesterol level below $3 \mathrm{mg} / \mathrm{dl}$ and $150 \mathrm{mg} / \mathrm{dl}$ respectively (low albumin cholesterol group; LAC). Group B had normal blood albumin and cholesterol level i.e. above $3.5 \mathrm{mg} / \mathrm{dl}$ and $220 \mathrm{mg} / \mathrm{dl}$ respectively (high albumin cholesterol group; HAC). These cows were administered $500 \mu \mathrm{g}$ cloprostenol sodium (Pragma $^{\circledR}$, Intas, India) intra-muscularly on tenth day of estrous. Ovsynch protocol was started from the thirteenth day with intramuscular dose of 20 microgram buserelin acetate $\left(\right.$ Gynarich $^{\circledR}$, Intas, India), $500 \mu \mathrm{g}$ cloprostenol sodium on day 20 and 20 microgram Buserelin acetate on day 22. All cows were inseminated twelve hours after the administration of last dose of buserelin acetate.

Cows returning to heat on or before day 22 and cows found pregnant on day 65 was noted and percentage calculated.

Blood samples were collected on day 12, 14, 16 and 18 of AI (day 0). Serum was separated and stored at $-20^{\circ} \mathrm{C}$ until use. Serum samples of cows returning to heat on or before day 22 in LAC group and found pregnant on day 65 in HAC group were assayed for progesterone by ELISA kit (Biogenix, India) following manufacturer's protocol.

Data was analyzed by t-test or chi-square test using SPSS software version 17.

\section{Results and Discussion}

Ovsynch protocol in low and high serum albumin-cholesterol groups of cross-bred cows resulted in conception rate of $10 \%$ (5 out of 50 inseminated cows) and 38\% (19 out of 50 inseminated cows) respectively that differed significantly (table 1). Among the non-pregnant cows of low and high serum albumin-cholesterol group of cows, the percentage of cows those returned to heat on or before day 22 of insemination was $60.7 \%$ 
and $32.3 \%$ respectively that differed significantly (table 2). Amongst cows in low serum albumin-cholesterol group, the cows those were found pregnant had significantly greater albumin and cholesterol level than those returned to heat on or before day 22 (Figure 2). The progesterone level of cows those returned to heat on or before day 20 in the low albumin-cholesterol group was significantly lower on day 12, 14, 16 and 18 than compared to those found pregnant on day 65 in the high albumin-progesterone group (Figure 1).

The conception rate of cows with Ovsynch protocol in high albumin-cholesterol group was above that reported by Chebel and Santos (2010)but below Machado et al., (2017); ( $25 \%$ and $38.4 \%$ respectively). However the conception rate of cows in the low albumincholesterol group in our work was $10 \%$ that is significantly lower than those reported by the aforementioned workers. This suggests that serum albumin and cholesterol concentration is one of the factors responsible for variation in conception rate with Ovsynch protocol.

Cholesterol is transported to the bovine ovary by the high density lipoproteins (HDL) and up-taken by the luteal cells for the synthesis of progesterone (Stocco et al., 2005, Roostaee et al., 2008). Cholesterol is metabolised and converted by the small and large luteal cells into progesterone. Almost $90 \%$ of the cholesterol used for the synthesis of progesterone is derived from the blood circulation in the form of HDL and only $10 \%$ is synthesised by the luteal cells (Harrison et $a l .$, 1987). This explains the low blood progesterone level in cows of low albuminchlolesterol group in our experiment. Further $90 \%$ of the synthesised progesterone is circulated in the blood bound to albumin and $10 \%$ remains free (Harrison et al., 1987). Thus hypo-albuminemia leads to further lowering of circulating progesterone.

Looking at the blood progesterone profile of cows between day 12 to 18 of insemination in the low albumin-cholesterol group (figure1), a declining trend can be appreciated that could be due to pre-mature release of endometrial $\mathrm{PGF}_{2 \alpha}$. It has been reported that in-adequate exposure of the bovine uterus to progesterone leads to pre-mature release of endometrial $\mathrm{PGF}_{2 \alpha}$ due to early up-regulation of oxytocin receptors (OTRs) (Demmers et al., 2001). Lack of progesterone pre-exposure leading to pre-mature luteolysis is further supported by the fact that first post-partum heats are often followed by short estrous cycles (Perea and Keith, 2007). Thus the cause of early embryonic death in the low albumincholesterol group can be explained by the low level of circulating progesterone and premature release of $\mathrm{PGF}_{2 \alpha}$ and early return to heat.

Table.1 Chi square analysis of low blood albumin and cholesterol level affecting the conception rate of cross bred cows with OvSynch Protocol

\begin{tabular}{|l|c|c|}
\hline & $\begin{array}{c}\text { Low Blood Albumin } \\
\text { Cholesterol Level }^{\mathbf{1}}\end{array}$ & $\begin{array}{c}\text { High Blood Albumin } \\
\text { Cholesterol Level }^{2}\end{array}$ \\
\hline Pregnant & $5(10 \%)$ & $19(38 \%)$ \\
\hline Non-pregnant & $45(90 \%)$ & $31(62 \%)$ \\
\hline Significance & \multicolumn{2}{|c|}{$\quad \mathrm{P}<0.01$} \\
\hline
\end{tabular}

1: blood albumin and cholesterol level below $3 \mathrm{mg} / \mathrm{dl}$ and $150 \mathrm{mg} / \mathrm{dl}$ respectively

2: blood albumin and cholesterol level above $3.5 \mathrm{mg} / \mathrm{dl}$ and $220 \mathrm{mg} / \mathrm{dl}$ respectively 
Table. 2 Chi square analysis of non-pregnant cows with low and high blood albumin cholesterol level those returned to heat on or before day 22 of insemination (RH22) or found non-pregnant on day 65 post insemination (NP65)

\begin{tabular}{|l|l|l|}
\hline & $\begin{array}{l}\text { Low Blood Albumin } \\
\text { Cholesterol Level }\end{array}$ & $\begin{array}{l}\text { High Blood Albumin } \\
\text { Cholesterol Level }^{\mathbf{2}}\end{array}$ \\
\hline RH22 & $30(60.7 \%)$ & $10(32.3 \%)$ \\
\hline NP65 & $15(39.3 \%)$ & $21(67.7 \%)$ \\
\hline Significance & P $<0.01$ & \\
\hline
\end{tabular}

Figure.1 Blood progesterone level of cows during day 12 to 18 post insemination with low blood albumin cholesterol level those returned to heat before day $20(n=15)$ and cows with high blood albumin cholesterol level those found pregnant on day $65(n=15)$

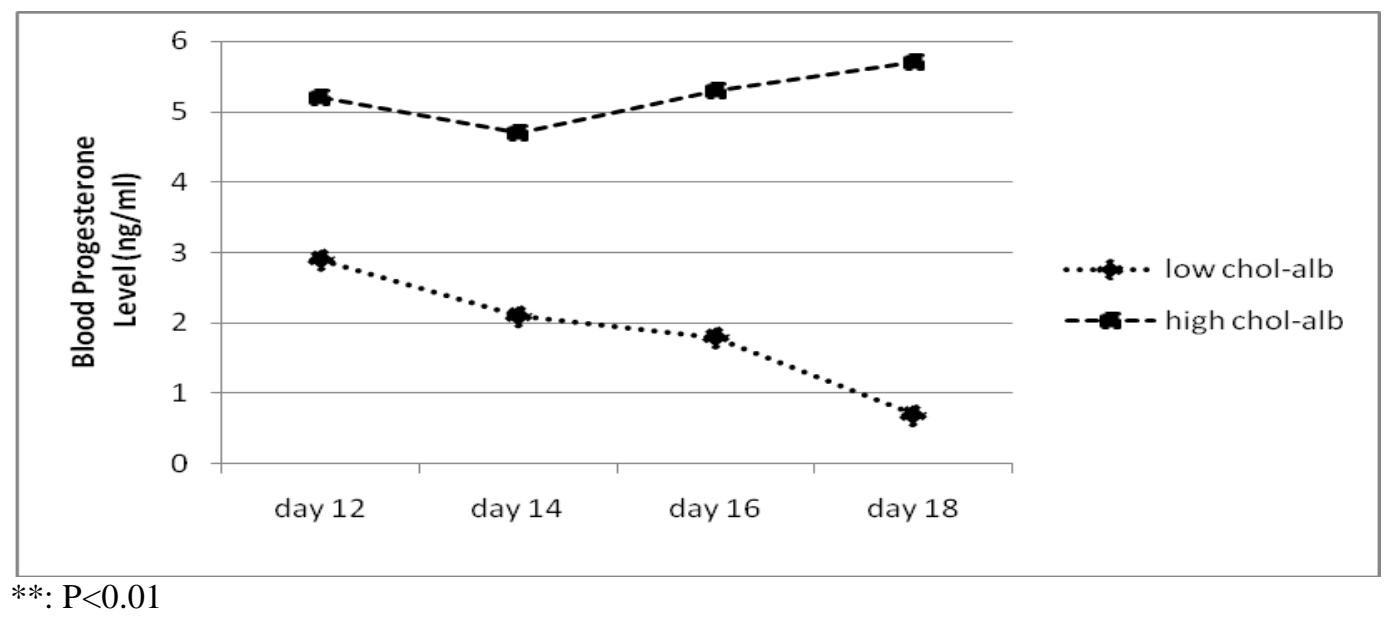

Figure.2 Difference in blood albumin and cholesterol level among pregnant $(n=5)$ and nonpregnant $(n=30)$ group of cross-bred cows those had general hypo albuminemia $(<3 \mathrm{mg} / \mathrm{dl})$ and cholesterolemia (<150 mg/dl)

A.

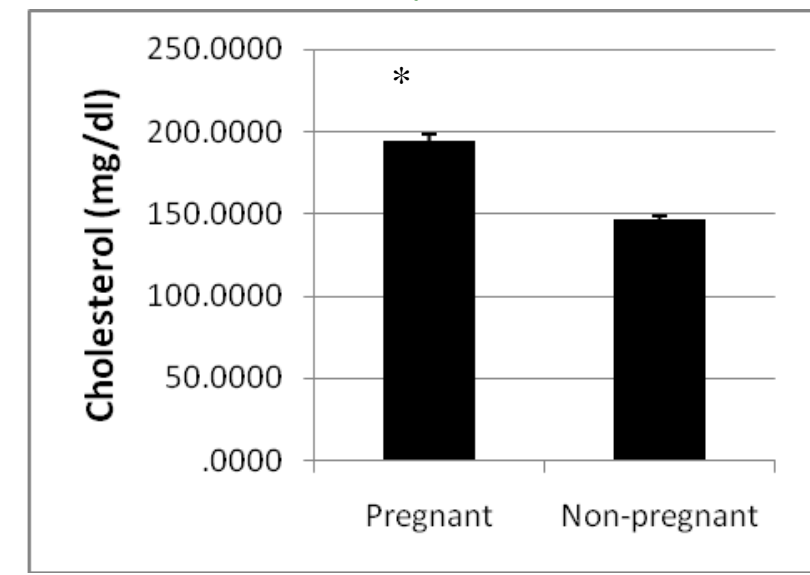

*: $\mathrm{P}<0.05$
B.

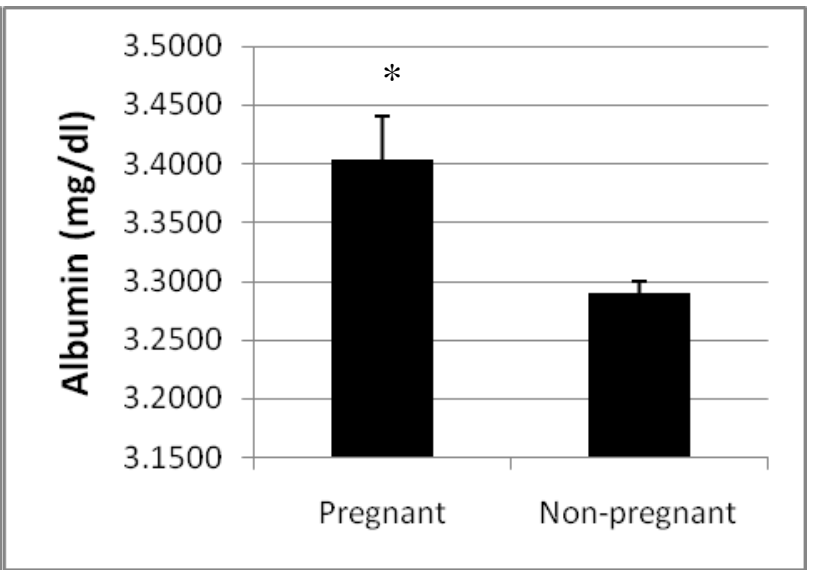


Hypo-albuminemia and hypo-cholesterolemia are very common in cattle post-partum due low feed intake, high milk yield, negative energy balance and sub-clinical fatty liver (Mostaghni and Askari, 1996) and subclinical forms of haemo-protozoan infection like carrier state of theileriosis (Saberet al.,2008) that is wide-spread in field conditions. One of the reasons for the variation in conception rate reported with Ovsynch protocol (Chebel and Santos, 2010 and Machado et al., 2017) could be the variable degree of hypo-albuminemia and hypo-cholesterolemia that was not studied by those workers. Our findings point to the fact that failure of conception in cows with hypoalbuminemia and hypo-cholesterolemia could be due to low level of circulating progesterone or might be due to early onset of luteolysis in these cows. This is further supported by the fact that amongst the low albumin-cholesterol group in our work, those found pregnant had higher level of albumin and cholesterol compared to cows those returned to heat on or before day 20 .

In conclusion, low blood albumin and cholesterol level lowers blood progesterone level and conception rate with Ovsynch protocol in cross-bred cows. Therefore cows should be monitored for blood albumin and cholesterol level before the start of Ovsynch protocol.

\section{References}

Chebel, R. C. and Santos, J. E. P. (2010). Effect of inseminating cows in estrus following a presynchronization protocol on reproductive and lactation performances. J. Dairy Sci.93:46324643.

Demmers, K. J., Derecka, K. and Flint, A. (2001). Trophoblast interferon and pregnancy. J. Reprod. 121: 41-49.

Harrison, N. L., Majewska, M. D.,
Harrington, $\mathbf{J}$.W and Barker, $\mathrm{J}$.L. (1987). Structure-activity relationships for steroid interaction with the gammaaminobutyric acid A receptor complex. J. Pharmacol. Exp. Ther. 241(1) 346353.

Jobst, S. M., Nebel, R. L., McGilliard, M. L.and Peizer. K. D. (2000). Evaluation of reproductive performance in lactating dairy cows with prostaglandin $\mathrm{F} 2 \alpha$, gonadotropin-releasing hormone and timed artificial insemination. J. Dairy Sci. 83: 2366-2372.

Mostaghni, K. and M. Askari. (1996). Changes in serum albumin, cholesterol and glucose concentrations in subclinical fatty liver syndrome in dairy cattle. Journal of Applied Animal Research10(1): 33-38.

Machado, V. S., Neves, R., Lima, F. S. and Bichalo, R. C. (2017). The effect of Presynch-Ovsynch protocol with or without estrus detection on reproductive performance by parity, and the longterm effect of these different management strategies on milk production, reproduction, health and survivability of dairy cows. Theriogenology93: 84-92.

Perea, F. G., Keith, I. E. (2007). Infertility associated with the duration of luteal phase in postpartum cows. ISSN 10221301. Assoc. Latin. Amer. Prod. Anim. 16(3): 175- 185.

Pursley, J. R., Kosorok, M. R. and Wiltbank, M. R. (1997a). Reproductive management of lactating dairy cows using synchronization of ovulation. $J$. Dairy Sci.80:301-306.

Pursley, J. R., Wiltbank, M. C., Stevenson, J. S., Ottobre, J. S., Garverick, H.A. and Anderson., L. L.(1997b). Pregnancy rates per artificial insemination for cows and heifers inseminated at asynchronized ovulation or synchronized estrus. J. Dairy 
Sci.80:295-300.

Roostaee, A., Barbar, E., Lehoux, J. G., Lavigne, P. (2008). Cholesterol binding is a prerequisite for the activity of the steroidogenic acute regulatory protein (StAR). Biochem. J. 412(3): 553-562.

Saber, A. P. R., Khorrami, M. and Nouri, M. (2008). Evaluation of Haematochemical Parameters in Crossbred Cattle Naturally Infected with Theileria annulata in Iran. Int. J. Dairy Sci.3: 205-209.

Stevenson, J. S., Kobayashi, Y.and Thompson, K.E. (1999). Reproductive performance of dairy cows in various programmed breeding systems including Ovsynch and combinations of gonadotropin releasing hormone and prostaglandin F2 $\alpha$. J. Dairy Sci.82:506515.

Stocco, D. M., Wang, X. J. Y., Manna, P. R. (2005). Multiple signalling pathways regulating steroidogenesis and steroidogenic acute regulatory protein expression: more complicated than we thought. Mol. Endocrinol. 19(11): 2647-2659.

Washburn, S. P., Silvia, W. J., Brown, C. H., McDaniel, B. T. and McAllister, A. J. (2002). Trends in reproductive performance in southeastern Holstein and Jersey DHI herds. J. Dairy Sci.85:244-251.

\section{How to cite this article:}

Sengupta, D. and Sheetal, S.K. 2020. Low Blood Albumin and Cholesterol Levels Affecting the Conception Rate of Cross Bred Cows with Ovsynch Protocol. Int.J.Curr.Microbiol.App.Sci. 9(08): 3249-3254. doi: https://doi.org/10.20546/ijcmas.2020.908.371 